por que ler...?

[ MARIA LUCIA BUENO ]

Professora do Instituto de Artes e Design da Universidade Federal de Juiz de Fora (MG). Doutora em Sociologia (IFCH-UNICAMP), com pós-doutorado em Sociologia da Arte, da Cultura e da Moda (EHESS e Université Paris-Est ). É autora, entre outros, de Artes plásticas no século XX: modernidade e globalização (Imprensa Oficial, 2001) e organizadora de Sociologia das artes visuais no Brasil (Senac, 2012).

E-mail: marialucia.bueno@gmail.com

\title{
Charles James, um astro sem atmosfera no mundo da moda
}

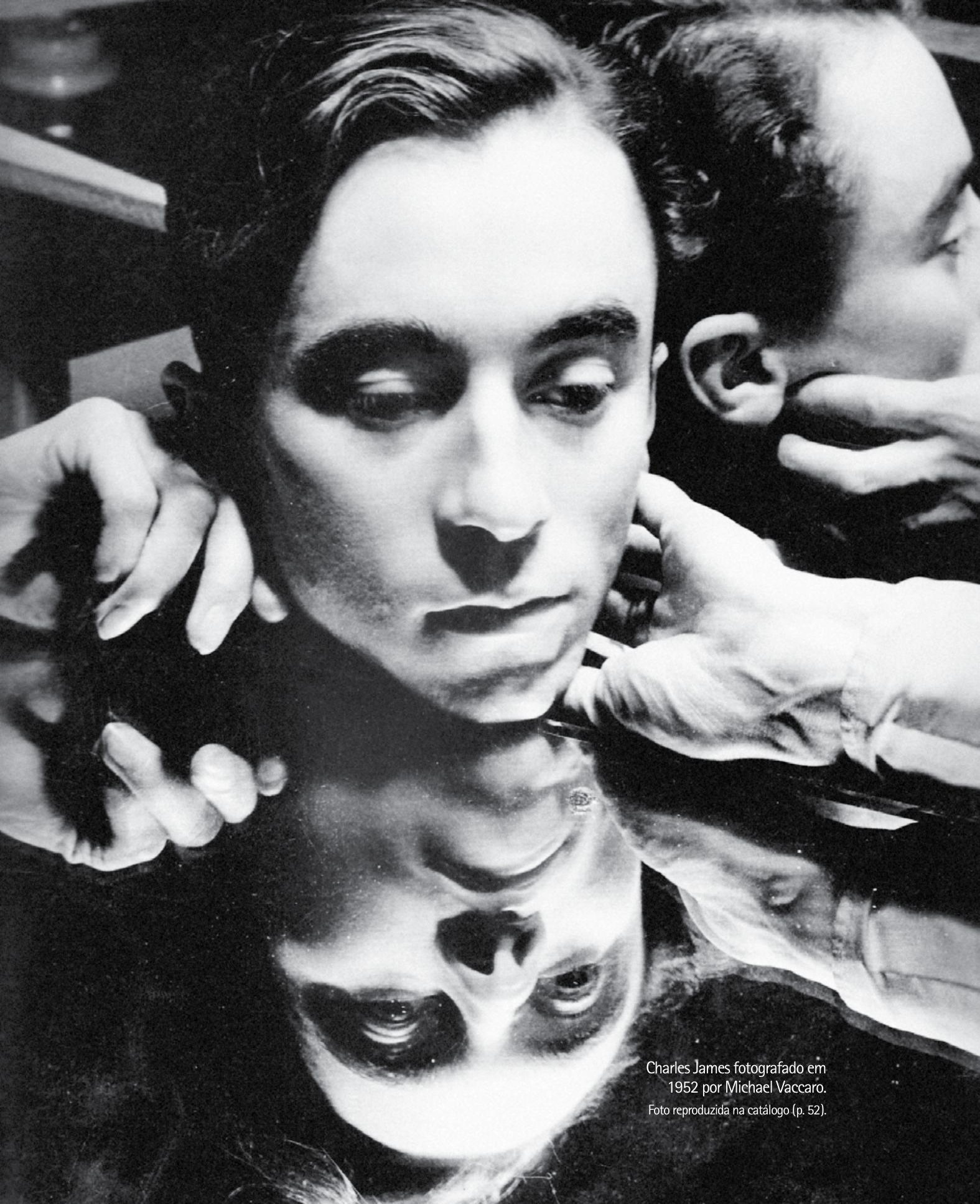


Estilistas como Christian Dior e Chanel, ícones na cultura de moda do século XX, tiveram seus nomes ligados a marcas prestígio que permanecem ativas. Na história da moda, as referências mais longevas e legitimadas geralmente estão associadas a uma grife ou a um perfume, os principais artífices da construção da memória do trabalho dos profissionais do setor. A importância histórica tornou-se proporcional ao peso econômico e simbólico das marcas, pois são elas que financiam as publicações, as grandes exposições, a manutenção do acervo material, as pesquisas, os filmes, os documentários, uma vez que é na perenidade da influência do costureiro que reside a sua força simbólica.

Charles James (Surrey, Reino Unido, 1906 - Nova York, Estados Unidos, 1978), um dos mais inventivos costureiros do período da alta-costura, o único que atuou a partir dos Estados Unidos, foi referência incontestável no mundo da moda do anos 1940 e 1950. Mas, em razão do seu fracasso comercial e por não ter seu nome associado a uma marca ou a um perfume, ficou quase esquecido, mantendo-se como uma lembrança vaga entre pesquisadores e profissionais da área - mesmo assim, a partir de referências muito restritas, como os vestidos de baile fotografados por Cecil Beaton. Porém, essa situação está prestes a se reverter com a inauguração, em maio de 2014, de uma exposição retrospectiva do costureiro organizada pelo Metropolitan Museum em Nova York, um dos mais influentes centros mundiais de exibição da moda. 0 catálogo da mostra, Charles James, beyond fashion, assinado pelos curadores Harold Koda e Jan Glier Reeder, recupera, apoiado em fontes inéditas, a trajetória desse designer visionário, cuja relevância da obra ultrapassou as fronteiras do mundo moda.

\section{Um outsider}

Irascivel, perdulário, atormentado, drogado, Charles James foi um personagem singular, cuja carreira e vida se assemelham mais com a de um artista outsider, do que com a do profissional da moda, que vestiu as mulheres mais ricas do seu tempo. Em sua trajetória, deparou-se com vários parceiros comerciais que se dispuseram a financiar sua produção por algum tempo. Entrou em conflito com todos eles e morreu quebrado.

Boa parte de sua obra, nos primeiros e nos últimos anos, foi criada em espaços alternativos, como quartos de hotéis. Numa época em que a maior parte dos nomes da alta-costura produzia a partir de estabelecimentos organizados em várias oficinas, contando com uma média de mil funcionários. Em 1937, a edição inglesa da Harper's Bazaar publicou um artigo sobre o costureiro, intitulado "Agonia criativa", com uma foto do performático James encenando um momento de reflexão no seu quarto-ateliê num hotel de luxo inglês. Em 1976, foi fotografado e filmado trabalhando em seu último quarto-ateliê, no Chelsea Hotel, tradicional reduto da boêmia artística e intelectual em Nova York.

\section{Vida e trajetória}

Charles James nasceu na Inglaterra, filho de um oficial inglês e uma milionária da alta sociedade de Chicago. Criado num ambiente elegante, com uma formação sólida em artes, particularmente em música e pintura, frequentou escolas de elite na Grã-Bretanha, nos Estados Unidos e na França, experiência que facilitou o desenvolvimento de sua carreira multinacional a partir da década de 1930. Desde cedo manifestou pendores artísticos, que se desenvolveram de forma mais consistente nos quatro anos que passou no Harrows College, tradicional estabelecimento inglês para meninos, onde descobriu o teatro, a performance, o figurino, e começou a se interessar pela criação de roupas. Ali também ficou amigo de Cecil Beaton, que veio a se tornar um dos principais fotógrafos de moda.

A inclinação para as artes, que evoluiu combinada ao homossexualismo e a um comportamento excêntrico, desagradou o pai, um militar autoritário e conservador, que procurou desviá-lo para uma carreira no mundo dos negócios. Por imposição paterna, foi trabalhar nos escritórios da Commonwealth Edison, em Chicago, sob a tutela do presidente Samuel Insull, amigo da família e pioneiro na indústria de eletricidade. Logo no início foi transferido para o departamento de arquitetura, onde eram projetadas as instalações industriais da empresa. Nessa passagem, de alguns meses, talvez um ano, aprendeu a dominar os conceitos de arquitetura e engenharia, que mais tarde viria aplicar no seu trabalho de costura. James, que se considerava autor de um International fashion style, teve o desenvolvimento de sua obra marcado pela cultura arquitetônica de Chicago. 
Em 1925, abandonou a emprego para se estabelecer como designer de chapéus, gerando um rompimento definitivo com o pai, que lhe bloqueou o acesso ao dinheiro da família. Porém, em contrapartida, encontrou respaldo entre os membros da comunidade industrial e comercial de Chicago, parentes e amigos de sua mãe, que desde 0 início reconheceram seu talento. Foi sua primeira clientela que, por décadas, 0 apoiou econômica e emocionalmente, não apenas comprando suas criações, mas também financiando seus empreendimentos. Seus chapéus e primeiras roupas esportes, que começou a produzir em seguida, tiveram repercussão no meio artístico de Nova York e receberam boa divulgação em revistas de moda como Vogue e Harper's Bazaar.

Completou sua formação em moda na Paris dos anos 1930. Na boêmia parisiense conheceu alguns de seus amigos e incentivadores: Elsa Schiaparelli, Jean Cocteau, que o salvou de uma de suas tentativas de suicídio, Christian Dior, na época apenas um marchand em dificuldades, e Paul Poiret, já completamente arruinado, e que foi um dos seus mentores. Frequentou os ateliês de Balenciaga e de Chanel, a quem creditava parte da sua formação, e que também foi uma de suas clientes.

Graças a heranças dos avós, que rapidamente se esgotaram, iniciou uma trajetória no mundo da alta moda europeia, transitando entre quartos de hotéis de luxo em Londres e Paris, que também funcionavam como ateliês de costura. Interpretando a alta-costura sob o viés da mentalidade industrial norte-americana, criava propostas extremamente elaboradas, que deveriam ser reproduzidas em larga escala. No decorrer da década de 1930, produzia esporadicamente pequenas coleções, de vinte e poucas peças, que desfilaram e foram comercializadas nas mais reputadas lojas de departamento em Londres, Chicago e Nova York.

Com a guerra, retornou aos Estados Unidos, estabelecendo-se em Nova York. Os anos 1940 e 1950 foram o grande momento profissional de Charles James, quando sua produção de moda adquiriu projeção e prestígio internacional, apesar dos sucessivos malogros comerciais de seus estabelecimentos. Datam dessa ocasião seus vestidos de baile, concebidos como esculturas e realizados a partir de cálculos matemáticos, que foram disputados pelas milionárias.

Nos anos 1960, com ascensão da cultura jovem, o desenvolvimento do mercado de massa e mudanças nos estilos de vida, a moda alta-costura foi se convertendo num anacronismo, e com ela a obra e a carreira de James. No final da década, encerrou sua atividade como designer para se dedicar a trabalhos experimentais em esculturas e a escrever sobre suas técnicas e métodos de construção de roupas. Em 1969, realizou uma retrospectiva multimídia de sua obra no Electric Circus, uma casa noturna em Nova York, com o suporte do estilista Halston, de sua ex-mulher Nancy James e de algumas clientes. Em 1975, ganhou uma bolsa Guggenheim para escrever um livro sobre sua metodologia para o design de roupas, intitulado Meta-Morphology or Fashion Engineering Procedures, que nunca foi concluído.

\section{Charles James, além da moda}

A profissão de estilista é marcada pela fugacidade. Criações em ciclos curtos, que despontam cercadas de publicidades, são rapidamente consumidas e superadas com o aparecimento de um novo ciclo. Muito diferente da maneira como Charles James concebia o seu ofício. Essa foi uma das principais causas da sua ruína.

Inventava roupas com o mesmo espírito que os arquitetos e designers imaginam seus edifícios e objetos, para serem utilizados e reproduzidos por um longo período, para permanecerem. Nunca para serem ultrapassados. Dialogando com a arquitetura e as artes, não criava estilos e tendências, mas formas, que retomava e aperfeiçoava em outras roupas. Obsessivo, embasado em conhecimentos de engenharia, projetava protótipos de roupas que podiam levar anos para serem finalizados, como foi o caso do seu conjunto Pagode, que demorou quatro anos para ficar pronto. Outro exemplo é o casaco Dolman de 1947, com mangas raglan enormes, idealizado para ser vestido por mulheres de diferentes tamanhos e pesos, que foi reproduzido em escala industrial em diferentes versões, por mais de dez anos.

0 tempo na produção de Charles James era pautado pela perfeição, "trabalhando às vezes por doze horas seguidas sobre uma costura: completamente extasiado, sem fome ou cansaço, até descobrir o lugar exato onde ela deveria ser colocada" (KODA; REEDER, 2014, p. 163). 0 mundo da moda é parte da esfera dos negócios, onde vigoram os prazos curtos. James vivia no reino da perfeição, onde todos os prazos eram 
rompidos em nome dela, mesmo que o levasse à beira da ruína. Essa postura radical foi a origem das divergências com todos os seus parceiros comerciais, que apesar da admiração que lhe dedicavam, eram tomados pelo desespero, acabavam rompendo definitivamente com ele.

Preocupado em estabelecer regras de antropometria que pautassem a produção industrial, centrou parte de sua energia para pesquisar uma maneira de aperfeiçoar 0 design de moda norte-americano. No entanto, suas investidas no mercado da Sétima Avenida foram todas fracassadas. Seu sistema de trabalho, pautado por ciclos pessoais variáveis, e com uma escala de produção muito reduzida, que já não era competitivo no âmbito da alta-costura, revelou-se totalmente inadequado para o mercado de massa da Sétima Avenida. Em quarenta anos, sua produção total não atingiu 1.000 peças de roupa. São números baixíssimos, se consideramos que Christian Dior, trabaIhando para uma clientela seleta da alta-costura, apresentava 200 novos modelos em cada coleção, sendo que nos dez anos em que esteve à frente de sua Maison, realizou 16 mil croquis e vendeu 100 mil vestidos (POCHNA, 1994, p. 335).

Apesar do fracasso comercial, e do temperamento difícil, desfrutou de considerável legitimidade simbólica no meio da moda, influenciando Dior e Balenciaga ${ }^{1}$, e tendo entre suas clientes fiéis as mulheres mais ricas e elegantes dos Estados Unidos, que não se importavam de esperar, muitas vezes meses, por um vestido de baile confeccionado por Charles James.

Embora as imagens mais conhecidas de suas roupas sejam os deslumbrantes vestidos de baile criados nos anos 1940 e 1950, e eternizados pelas lentes de Cecil Beaton, considerava que as peças de alfaiataria foram o seu principal trabalho, a sua real contribuição para o design de vestuário nos Estados Unidos.

Mesmo com todos os altos e baixos de sua carreira James, manteve uma convicção inabalável no valor e na importância de sua obra, tendo se preocupado com sua preservação. Solicitava às clientes que doassem as roupas adquiridas para o Brooklyn Museum, que se converteu no principal depositário de seu acervo. 0 museu também organizou, nos anos 1960, os primeiros cursos de design de moda com base no cálculo e na engenharia, ministrados por Charles James, e que a seguir foram replicados, sempre com o costureiro à frente, em várias instituições, entre as quais a Rodhe Island School of Design e o Pratt Institute. Ali também ocorreu, em 1988, a primeira e única retrospectiva de sua obra.

A exposição e a publicação organizadas em 2014 pelo Costume Institute, do Metropolitan Museum em Nova York, tiveram como principais subsídios duas fontes: a coleção de roupas do Brooklyn Museum, arrolada a partir de doações de suas clientes, adquirida e restaurada pelo MET em 2009, e os arquivos pessoais do designer - com os seus protótipos, desenhos, moldes, anotações e registros pessoais -, doados por Homer Layne, seu último assistente. Com base nesse material foi possivel uma reconstrução da metodologia e técnica do costureiro, assim como de sua trajetória pessoal, com a colaboração dos filhos de James.

Charles James, beyond fashion, organizado por Harold Koda, curador do Costume Institute do Metropolitan, e Jan Glier Reeder, curador do Brooklyn Museum Costume Collection, é o resultado desse esforço, apresentando uma documentação até então desconhecida, que lança novas perspectivas para pensar a obra do costureiro e a produção de moda no período. Nesse sentido, merece destaque a cronologia detalhada da vida e do percurso profissional de James, traçada a partir de pesquisa exaustiva realizada Glier Reeder. Paralelamente, os curadores apresentam uma sequência de textos analisando o processo de trabalho do costureiro. Encerrando o volume, está o artigo dos conservadores do Metropolitan, Sarah Scaturro e Glenn Petersen, com um relato sobre o estado das peças de Charles James quando iniciaram a atividade de restauração, salientando os desafios encontrados no decorrer do processo.

\section{Por dentro do mundo da moda}

Boa parte das exposições apresentadas no Metropolitan Museum - e nos demais museus que exibem moda - são patrocinadas por marcas de prestígio e envolvem estilistas que de alguma maneira se encontram vinculados a elas. Nos últimos anos, alguns dos mais destacados costureiros da alta-costura da primeira metade do século XX ressurgiram em retrospectivas financiadas por grandes empresas, com o intuito 
de reativá-los enquanto marca. Foi o que ocorreu com Madeleine Vionnet (GOLBIN, 2009) e Jeanne Lanvin (MERCERON, 2007).

A retrospectiva e o catálogo sobre James, assim como a restauração de parte do acervo adquirido do Brooklyn Museum, foram custeados com os fundos do Metropolitan e apoio da editora Conde Nast, com a qual o museu vem firmando parceria nos últimos anos, tendo por finalidade recuperar a trajetória de um dos principais expoentes da moda norte-americana. No entanto, o impacto da exposição foi surpreendente em todos os sentidos, reabilitando não apenas a memória do costureiro, mas também o valor estético e cultural de sua obra no meio artístico e intelectual. Essa legitimação simbólica num curto espaço de tempo converteu-se em valor econômico, com o nome do designer sendo negociado como marca de prestígio por uma grande empresa norte-americana. Em menos de dois meses, pelo poder de transfiguração simbólica do Metropolitan Museum, Charles James, um astro sem atmosfera, saiu do ostracismo em que esteve confinado por mais de três décadas, para ocupar um espaço de destaque na história e no mundo da moda.

1] Foi considerado por Dior "o maior talento da minha geração" e por Balenciaga "o único costureiro a elevar [a moda] de uma arte aplicada a uma forma de arte pura" (THURMAN, 2014).

\section{REFERÊNCIAS}

GOLBIN, Pamela. Madelaine Vionnet, puriste de la mode. Paris: Les Arts Decoratifs, 2009

KODA, Harold; REEDER, Jan Glier. Charles James: beyond fashion. London/New Haven: Yale University

MERCERON, Dean L Lanvin. New York: Rizzoli, 2007.

POCHNA Marie-France. Christian Dior. Paris: Flammarion, 1994.

THURMAN, Judith. Dressing up: how Charles James elevated American fashion. The New Yorker, 5 maio 2014.

\section{CRONOLOGIA}

1906 - Charles Wilson Brega James nasce em 18 de julho na Inglaterra.

1920-23 - Ingressa na Harrow's School.

1923 - Estágio na Universidade de Bordeaux.

1924 - Muda para Chicago para trabalhar na Commonwealth Edison.

1925 - Abandona a empresa para se dedicar à produção de chapéus.

1926 -1929 -Abre a Boucheron (design de chapéus roupas).

1929 - Cria o Taxi Dress, primeiro uso de moda do zíper, reproduzido pelas confecções inglesas e norteamericanas e divulgado na Voguee na Harper's Bazaar.

1930 - 1939 - Trabalha entre Londres, Paris e Nova York. Em 1934 se fixa em Paris. Suas criações recebem cobertura da mídia.

1939 - Muda para Nova York. Contrata um alfaiate que trabalhou para Vionnet.

1942 - Promove oficinas para a formação de designers no Brooklyn Museum.

1943 - Abre showroom para vender suas criações no espaço de Elisabeth Arden.

1944 - 1959 - Auge da carreira e do prestígio. Fica famoso por seus vestidos de baile.

1954 - Casa com a milionária Nancy Gregory.

1961 - 1978 - Nos anos 1960, com a decadência da moda de luxo, concentra as atividades no ensino e na pesquisa.

1964 - Fim do casamento. Muda para o Chelsea Hotel, onde vive e trabalha

1966 - Desenvolve projetos de esculturas flexiveis.

1969 - Grande retrospectiva em Nova York. 